\title{
Maria di Francia, Il Purgatorio di san Patrizio
}

\section{Walter Meliga}

\section{Q OpenEdition}

\section{Journals}

\section{Edizione digitale}

URL: https://journals.openedition.org/studifrancesi/40332

DOI: 10.4000/studifrancesi.40332

ISSN: 2421-5856

\section{Editore}

Rosenberg \& Sellier

\section{Edizione cartacea}

Data di pubblicazione: 1 juillet 2004

Paginazione: 158

ISSN: 0039-2944

\section{Notizia bibliografica digitale}

Walter Meliga, «Maria di Francia, II Purgatorio di san Patrizio», Studi Francesi [Online], 142 (XLVIII | I) |

2004, online dal 30 novembre 2015, consultato il 09 septembre 2021. URL: http://

journals.openedition.org/studifrancesi/40332 ; DOI: https://doi.org/10.4000/studifrancesi.40332

\section{Questo documento è stato generato automaticamente il 9 septembre 2021.}

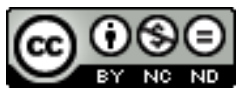

Studi Francesi è distribuita con Licenza Creative Commons Attribuzione - Non commerciale - Non opere derivate 4.0 Internazionale. 


\title{
Maria di Francia, Il Purgatorio di san Patrizio
}

\author{
Walter Meliga
}

\section{NOTIZIA}

MARIA DI FRANCIA, Il Purgatorio di san Patrizio, A cura di Giosuè LACHIN, Roma, Carocci, 2003, pp. 379, («Biblioteca medievale», 88).

1 L'Espurgatoire seint Patriz, il volgarizzamento che Maria di Francia fece del cosiddetto Tractatus de Purgatorio sancti Patricii rappresenta una tappa importante nel percorso che tra XII e XIII secolo porta alla stabilizzazione, nella teologia come nella credenza comune, di un luogo oltremondano intermedio tra Paradiso e Inferno, ovvero alla «nascita del Purgatorio», secondo il titolo di un noto libro di Jacques Le Goff. Questa nuova e accurata edizione del volgarizzamento presenta un'ampia introduzione storica (da tenere presente, proprio accanto a Le Goff, per la ricchezza e la precisione dei dati); il testo dell'Espurgatoire, edito secondo criteri di moderato interventismo e che permettono sempre di ricavare il dettato dell'unico testimone manoscritto, accompagnato dalla traduzione italiana a fronte; un approfondito commento linguistico ed esegetico; infine l'edizione di una versione del Tractatus, accompagnata anch'essa da note. 